\title{
Leonardo da Vinci
}

\section{Die Schöne und das Biest}

\author{
Sie ist nicht ganz so berühmt wie die Mona Lisa, \\ aber sicher nicht von minderer Qualität. Die „Dame \\ mit dem Hermelin" hängt in einem Krakauer \\ Museum und damit etwas abseits der internationalen \\ Kunstmetropolen. In der Kunstgeschichte nimmt \\ sie jedoch einen zentralen Platz ein. Ebenso wie bei \\ der großen Schwester in Paris, zeigt sich auch hier, \\ dass kein anderer Künstler die Subtilität und \\ Vieldeutigkeit im Ausdruck des menschlichen \\ Gesichtes so virtuos zu inszenieren vermochte wie \\ Leonardo da Vinci. Aber seine Bilder lösen nicht nur \\ Bewunderung aus. Sie geben auch Rätsel auf.
}

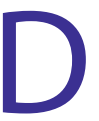
ie historische Einordnung des Bildes „Dame mit dem Hermelin"darf als weitgehend gesichert gelten. Obwohl das Porträt keinen Namen trägt, sind sich die Kunsthistoriker überwiegend einig, dass es sich bei der Dargestellten um Cecilia Gallerani (1473-1536) handelt. Sie zählte, als das Bild entstand, gerade einmal 18 Lenze und war die Geliebte des mächtigen Mailänder Fürsten Ludovico Sforza.

Auch auf die Frage, warum die Dame den possierlichen kleinen Vierbeiner in Händen hält, gibt es plausible Antworten. Das Hermelin, das im wirklichen Leben eher ein stinkendes und bissiges kleines Raubtier ist, galt als Schutztier der Schwangeren. 1491 entsprach das durchaus der Lebenssituation der Porträtierten, die damals einen Sohn des Fürsten erwartete. Im Übrigen lautete die griechische Bezeichnung für Hermelin Galée, was eine originelle Anspielung auf den Namen Gallerani ermöglichte.

Die Renaissance war die erste Blütezeit der Porträtmalerei, und schnell hatte sich auch für das weibliche Antlitz ein gewisser Stereotyp herausgebildet. Die hohe Stirn, das zaghafte Lächeln mit geschlossenen Lippen, die jugendlich ebenmäßigen Züge - all das summierte sich zu einer standardisierten Lieblichkeit in reizend herkömmlichen Gesichtchen.

Leonardos Darstellung erfüllt diese Schönheitsideale auf das trefflichste - und ist dennoch völlig unkonventionell. Während normalerweise die Porträtierte den Betrachter aus dem Bild heraus anschaut, ist der Blick Cecilias von etwas eingenommen, das außerhalb des Bildes liegt. Wem gilt ihre Aufmerksamkeit? Was ist so interessant, dass selbst das Wiesel sich verrenkt, um in die gleiche Richtung zu schauen? Über diese Fragen streiten Kunsthistoriker seit Jahrhunderten fast so intensiv wie über das Lächeln der Mona Lisa.
"Dame mit dem Hermelin",

1491/92,

Leonardo da

Vinci

(1452-1519)

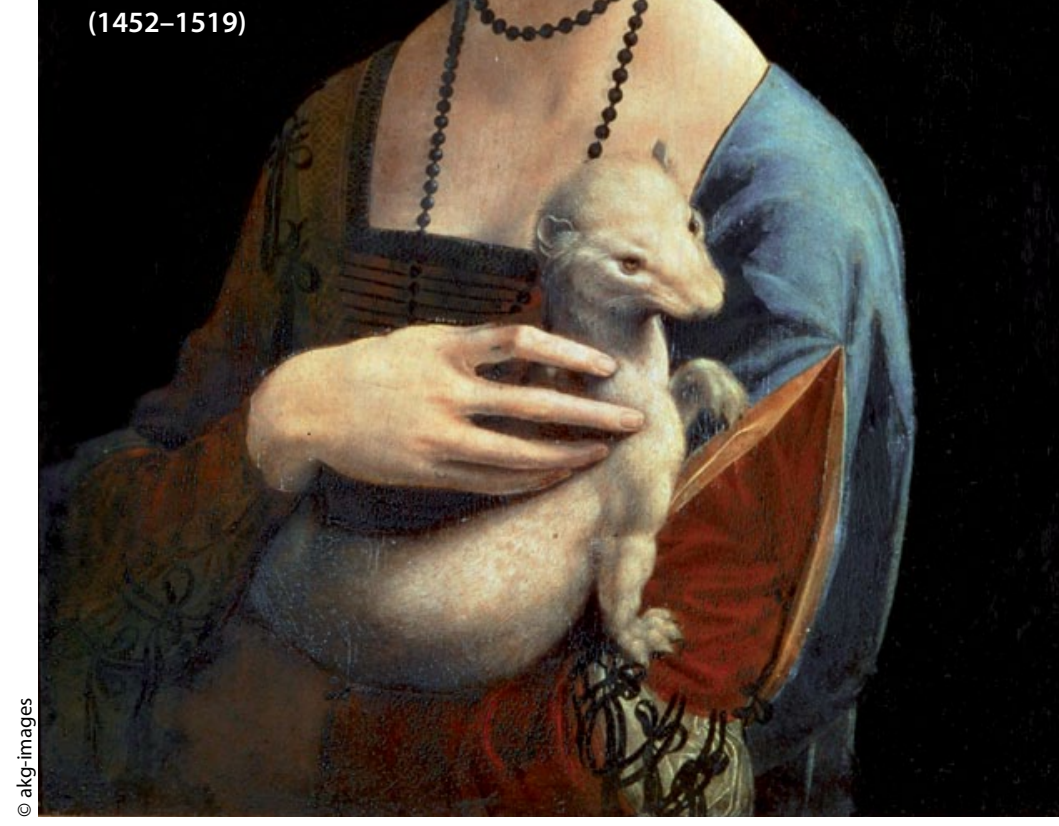

Für mich ist jedoch etwas anderes das Rätselhafteste: die Hand Cecilias. Zusammen mit dem Hermelin bildet sie den optischen Mittelpunkt des Porträts. Und dieser ist höchst irritierend. Im Verhältnis zu der zartgliedrigen Cecilia ist diese Hand nämlich viel zu groß, zu knochig und darüber hinaus seltsam verspannt. Irgendwie passt sie überhaupt nicht zu dem Gesicht. Es scheint fast, als gehöre sie jemand anderen.

Hat sich Leonardo vielleicht einfach ein wenig in der Perspektive vertan? Hat er - wie viele seiner Kollegen - vielleicht mit Versatzstücken gearbeitet und beim Zusammenfügen derselben nicht genau darauf geachtet, ob auch alles zusammenpasst? Bei manch anderen Malern, die Bilder geradezu fabrikmäßig herstellten, mag das als Erklärung durchgehen. Aber bei Leonardo? Der Maler, der wie kein anderer Proportionen geradezu mathematisch studierte und als erster Künstler überhaupt eigene anatomische Studien unternahm - ausgerechnet der soll bei der Perspektive und Anatomie derart daneben gelegen haben? Schwer zu glauben.

Eine andere Lösungsmöglichkeit: Vielleicht war Leonardo gar nicht an einer realistischen Darstellung gelegen. Vielleicht sollen Hand und Hermelin auf etwas ganz anderes hinweisen. In Neapel war kurz zuvor ein „Orden vom Hermelin“ gegründet worden, dessen Mitglied Ludovico Sforza war. Brauchte es für diesen Orden vielleicht eine besonders starke Hand? Möglicherweise schreibt ein geschickter amerikanischer Unterhaltungsschriftsteller über diese Frage mal wieder einen Bestseller. Fest steht auf jeden Fall: Leonardos Porträts faszinieren nicht nur, weil sie großartige Personendarstellungen sind. Sie irritieren auch immer wieder durch viele eingebaute kleine Rätsel. Und das auch nach mehr als 500 Jahren.

Prof. Dr. med. B. Kleine-Gunk, Fürth 